\title{
Preclinical Testing of an Oncolytic Parvovirus: Standard Protoparvovirus H-1PV Efficiently Induces Osteosarcoma Cell Lysis In Vitro
}

\author{
Carsten Geiss ${ }^{1,+}$ (D) Zoltán Kis ${ }^{1,2,3,+}$ (D), Barbara Leuchs ${ }^{1}$, Monika Frank-Stöhr ${ }^{4}$, \\ Jörg R. Schlehofer ${ }^{1}$, Jean Rommelaere ${ }^{1}$, Christiane Dinsart ${ }^{1}$ (D) and Jeannine Lacroix ${ }^{1,5, *}$ \\ 1 Division of Tumor Virology, Program Infection, Inflammation and Cancer, German Cancer Research \\ Center (DKFZ), Im Neuenheimer Feld 242, 69120 Heidelberg, Germany; cargeiss@uni-mainz.de (C.G.); \\ z.kis10@imperial.ac.uk (Z.K.); b.leuchs@dkfz-heidelberg.de (B.L.); joteres@arcor.de (J.R.S.); \\ j.rommelaere@dkfz-heidelberg.de (J.R.); c.dinsart@dkfz-heidelberg.de (C.D.)

Received: 1 September 2017; Accepted: 26 September 2017; Published: 17 October 2017

\begin{abstract}
Osteosarcoma is the most frequent malignant disease of the bone. On the basis of early clinical experience in the 1960s with $\mathrm{H}-1$ protoparvovirus (H-1PV) in osteosarcoma patients, this effective oncolytic virus was selected for systematic preclinical testing on various osteosarcoma cell cultures. A panel of five human osteosarcoma cell lines (CAL 72, H-OS, MG-63, SaOS-2, U-2OS) was tested. Virus oncoselectivity was confirmed by infecting non-malignant human neonatal fibroblasts and osteoblasts used as culture models of non-transformed mesenchymal cells. H-1PV was found to enter osteosarcoma cells and to induce viral DNA replication, transcription of viral genes, and translation to viral proteins. After H-1PV infection, release of infectious viral particles from osteosarcoma cells into the supernatant indicated successful viral assembly and egress. Crystal violet staining revealed progressive cytomorphological changes in all osteosarcoma cell lines. Infection of osteosarcoma cell lines with the standard H-1PV caused an arrest of the cell cycle in the G2 phase, and these lines had a limited capacity for standard H-1PV virus replication. The cytotoxicity of wild-type H-1PV virus towards osteosarcoma cells was compared in vitro with that of two variants, Del H-1PV and DM H-1PV, previously described as fitness variants displaying higher infectivity and spreading in human transformed cell lines of different origins. Surprisingly, wild-type H-1PV displayed the strongest cytostatic and cytotoxic effects in this analysis and thus seems the most promising for the next preclinical validation steps in vivo.
\end{abstract}

Keywords: osteosarcoma; protoparvovirus H-1 (H-1PV); oncolytic virus; viral cytotoxicity

\section{Introduction}

In children and adolescents, cancers are the diseases with the highest mortality [1,2]. Osteosarcoma is the most common type of primary bone cancer and the eighth most common form of pediatric cancer [3]. Current treatment strategies, introduced in the 1980s, include neo-adjuvant chemotherapy, resection of all primary and metastatic lesions, and subsequent adjuvant chemotherapy [4-6]. These 
strategies achieve average 5-year survival rates of $60-70 \%$. Approximately $20 \%$ of osteosarcoma patients initially present with metastatic disease, predominantly in the lungs. In metastatic osteosarcoma patients, the 5-year survival rate is drastically reduced to 15-30\% [6,7]. Especially for patients with high-risk or metastatic disease, novel treatment approaches are urgently needed. Among the targeted therapies now available to refractory or relapsed osteosarcoma patients and having shown first survival benefits [8], immunomodulatory approaches stimulating the antitumor immune response are considered the most promising $[9,10]$.

Oncolytic viruses are a class of promising, potent, and highly specific anticancer agents, combining specific cytotoxicity towards transformed cells with an immunotherapeutic action [11-13]. These viruses induce lytic infection of malignant cells and thereby stimulate the innate and adaptive immune systems by promoting the availability of tumor antigens which initiate cross-priming and vaccination effects $[11,14]$. The use of such viruses can also be synergistically combined with other treatment modalities inducing immunogenic cancer cell death [15]. The efficacy of several oncolytic viruses has been proven through in vivo preclinical osteosarcoma studies. In a study where wild-type oncolytic Seneca Valley Virus was tested on six human osteosarcoma-xenograft severe combined immuno-deficient mouse models, only two models showed significantly extended event-free survival and no model displayed any effect on overall survival [16]. In another study, the wild-type Semliki Forest Virus was found to increase dramatically the survival of osteosarcoma-xenograft nude mice [17]. In xenograft mice with localized or metastatic osteosarcoma, the recombinant, conditionally replicating adenoviruses Ad5- $\triangle 24 R G D$, Ad-OC-E1a, and Adenovirus VCN-01 significantly delayed tumor growth (localized tumors) or reduced number of metastatic lesions (pulmonary metastases) [18-21]. In the first phase I clinical trial of the naturally occurring reovirus isolate Reolysin in pediatric sarcoma patients (including osteosarcoma patients), safety data have been published [22].

The rodent protoparvovirus $\mathrm{H}-1(\mathrm{H}-1 \mathrm{PV})$ is another promising therapeutic agent. Its clinical safety upon intratumoral or intravenous injection has been demonstrated in a recently published first phase I/IIa clinical trial recruiting adult glioblastoma patients [23]. H-1PV is a wild-type oncolytic virus occurring naturally in rats. A natural tropism of this virus for the developing skeleton has been hypothesized, as infection in utero in embryonic rodents induces craniofacial dysmorphisms in successfully infected animals [24]. First-in-man applications of this wild-type rodent parvovirus in two adolescent osteosarcoma patients in the 1960s were prompted by the discovery that has oncolytic potential $[25,26]$. In this compassionate use study, no severe virus-induced toxicity was reported. Thereafter, more than four decades elapsed before the first phase I virotherapy trials with other oncolytic viruses started to recruit osteosarcoma patients [27]. To prepare for a clinical trial of H-1PV in osteosarcoma patients, systematic preclinical research is needed.

Protoparovirus H-1PV consists of an approximately 5.1-kb single-stranded DNA genome enclosed in a 25-nm non-enveloped icosahedral shell. The viral genome contains two main transcriptional units: one encoding the non-structural (NS) proteins and one encoding the viral capsid proteins (VP) and the small alternatively translated (SAT) $[27,28]$. The major large non-structural protein NS1 is essential to virus replication and cytotoxicity in permissive cells [28].

In H-1PV-infected animals and humans, the immune system produces virus-specific antibodies 5-7 days after infection, and these at least partially neutralize the virus [25,26]. Additionally, H-1PV triggers anticancer vaccination effects, whereby animals cured of cancer by the oncolytic virus remain immune to the same malignant disease even in the absence of the virus [29].

In recent years, H-1PV fitness mutants have been isolated and tested for antineoplastic efficacy [30]. It has been hypothesized that the greater egress of infective viral progeny viruses and the higher infectivity observed in vitro with these mutants may lead to higher antineoplastic efficacy in vivo. This has been confirmed for Del H-1PV in pancreatic cancer and cervix carcinoma xenograft models [30].

Here, as a first step in assessing the responsiveness of osteosarcomas to parvovirus treatment, preclinical testing of wild-type H-1PV and of two derived mutants, Del H-1PV, and DM H-1PV, has been performed in vitro. 


\section{Materials and Methods}

\subsection{Ethics Statement}

Human neonatal foreskin fibroblasts were supplied by CET celleng-tech (Coralville, IA, USA). Primary human osteoblasts were obtained from PromoCell GmbH (Heidelberg, Germany). All other osteosarcoma cell lines (CAL 72, H-OS, MG-63, SaOS-2, and U2-OS) were obtained from Cell Line Service GmbH (Eppelheim, Germany). The WAC-2 clone, derived from the neuroblastoma cell line SH-EP by stable transfection, contains an ectopic Cytomegalovirus N-myc proto-oncogene (CMV-MYCN) enhanced expression cassette [31] was kindly provided by Prof. Dr. med. O. Witt, Clinical Cooperation Unit Pediatric Oncology, German Cancer Research Center (Heidelberg, Germany). For data confirmation, a second batch was obtained from Prof. A. Schramm, Department of Pediatric Hematology and Oncology, University Hospital Essen (Essen, Germany).

\subsection{Mammalian Cell Culture}

All cell cultures were maintained in $5 \% \mathrm{CO}_{2}$ at $37^{\circ} \mathrm{C}$ and $100 \%$ relative humidity. Human neonatal foreskin fibroblast cells were propagated in Human Foreskin Fibroblast Expansion Medium (Cellular Engineering Technologies, Coralville, IA, USA) containing 10\% fetal calf serum (FCS), $100 \mathrm{U} / \mathrm{mL}$ penicillin, and $100 \mu \mathrm{g} / \mathrm{mL}$ streptomycin. Non-transformed human osteoblasts were grown in Osteoblast Growth Medium (PromoCell GmbH, Heidelberg, Germany). The culture medium for osteosarcoma cell lines was Dulbecco's Modified Eagle's Medium (DMEM) or Minimum Essential Medium (MEM) for H-OS cells, supplemented with $2 \mathrm{mM} \mathrm{L-glutamine,} 10 \%$ fetal bovine serum, $100 \mathrm{U} / \mathrm{mL}$ penicillin, and $100 \mu \mathrm{g} / \mathrm{mL}$ streptomycin (final concentrations). The human neuroblastoma cell line WAC-2 was cultured in Roswell Park Memorial Institute (RPMI-1640) medium containing $10 \%$ fetal bovine serum, $100 \mathrm{U} / \mathrm{mL}$ penicillin, and $100 \mu \mathrm{g} / \mathrm{mL}$ streptomycin. For passaging, cells were detached in $0.05 \%$ or $0.25 \%$ Trypsin-EDTA solution and then resuspended in fresh culture medium. All cell lines and non-transformed cell cultures were routinely checked for contamination [32] and genomic identity [33], using previously established methods. Osteosarcoma cell lines used in this study are listed in Table S1.

\subsection{Viruses and Virus Production}

Wild-type $\mathrm{H}-1$ parvovirus (H-1PV) and the recombinant $\mathrm{H}-1$ parvovirus (Chi-hH-1/EGFP) expressing enhanced green fluorescent protein (EGFP) were produced at the Virus Production \& Development Unit, Division of Tumor Virology, German Cancer Research Center, Germany. The recombinant parvovirus Chi-hH-1/EGFP was obtained by co-transfecting HEK-293T cells with the corresponding recombinant vector DNA and a helper plasmid expressing the viral capsid genes in trans [34]. It was purified in the same manner as the wild-type H-1PV. H-1PV was produced by infecting human newborn embryonic kidney NBK-324K cells at a multiplicity of infection (MOI) of $10^{-2}$ plaque-forming units per cell (PFU/cell). Four to five days after infection, the crude virus was extracted from infected cells and purified by filtration (pore diameter: $0.2 \mu \mathrm{m}$ ) and by iodixanol gradient centrifugation as previously described [35]. Contamination of virus stocks with endotoxins was below $2.5 \mathrm{U} / \mathrm{mL}$. The Del H-1PV mutant was produced as previously described [30].

\subsection{Detection of Infectious $H-1 P V$ Particles}

Viral titers were determined by means of infected cell hybridization assays or by plaque assay as previously described [36]. Titration experiments were carried out in triplicates. For the hybridization assay, NB-324K cells $\left(7.6 \times 10^{3}\right.$ cells / well $)$ were seeded into 96-well plates. The cells, $24 \mathrm{~h}$ after seeding, were infected with 10 -fold serial dilutions of the virus sample and incubated for $72 \mathrm{~h}$ under $5 \% \mathrm{CO}_{2}$, at $37^{\circ} \mathrm{C}$ and $100 \%$ relative humidity. Next, the cells were lysed with $0.75 \mathrm{M} \mathrm{NaOH}$. The DNA was transferred to a nylon membrane, UV-cross-linked, hybridized with a ${ }^{32} \mathrm{P}$-labeled NS-specific DNA fragment, and used to expose $\mathrm{X}$-ray films for autoradiography. 


\subsection{Western Blot Analysis}

Western blotting was performed as described [37]. The cells, $12 \mathrm{~h}$ after seeding, were either mock-infected or exposed to wild-type H-1PV (MOI: 1 PFU/cell). Osteosarcoma cells were harvested at 24-h intervals over a 5-day period post-infection. Briefly, approximately $10^{6}$ mock- or H-1PV-infected cells were harvested at the time points indicated, collected by centrifugation, and washed with phosphate-buffered saline (PBS). Cell pellets were kept on ice for $1 \mathrm{~h}$ in RIPA lysis buffer with freshly added protease inhibitor (complete Mini, EDTA-free, Roche Diagnostics, Indianapolis, IN, USA) and then centrifuged at $15,000 \times \mathrm{g}$ for $10 \mathrm{~min}$ at $4{ }^{\circ} \mathrm{C}$. The supernatants were stored at $-80{ }^{\circ} \mathrm{C}$ until further analysis. Protein concentrations of the cell lysates were determined photometrically with the Pierce $^{\mathrm{TM}}$ BCA Protein Assay Kit (Thermo Fisher Scientific, Waltham, MA, USA), according to the manufacturer's protocol. Twenty micrograms of each cell lysate was resolved by $10 \%$ sodium dodecyl sulfate polyacrylamide gel electrophoresis (SDS-PAGE) and transferred to a nitrocellulose membrane (Schleicher \& Schüll, Kassel, Germany).

The following antibodies were used: monoclonal mouse anti-actin clone C4 (MP Biomedicals, Illkirch, France), rabbit polyclonal antiserum MK3 raised against the viral NS1 protein, kindly provided by N. Salomé, INSERM U1109, Strasbourg, France [36]. Binding of antibodies, detection with horseradish peroxidase-conjugated anti-rabbit or anti-mouse IgGs (dilution 1:5000), and chemiluminescence assays were performed as previously described [38].

\subsection{Microscopy}

Comparative fluorescence and phase contrast images were recorded under an Olympus CKX41 inverted phase contrast microscope (Olympus Corporation, Tokyo, Japan) using the Cell B software from Olympus. Phase contrast images were captured with the Keyence BZ 9000 microscope (KEYENCE Microscope Europe NV/SA, Mechelen, Belgium) and the imaging softwares BZ II Viewer and BZ II Analyzer supplied with it by the manufacturer.

\subsection{Viral DNA Extraction and Quantitative Real-Time Polymerase Chain Reaction ( $q P C R$ )}

One-tenth of the total volume, i.e., $1 \mathrm{~mL}$, of the culture medium of adherently growing cells was collected from each cell culture dish at regular intervals post-infection before harvesting the cells for protein extraction and subsequent western blot analysis (see Section 2.5). This supernatant was subjected to alkaline lysis in $1 \mathrm{M} \mathrm{NaOH}$ in TE buffer for $30 \mathrm{~min}$ at $56^{\circ} \mathrm{C}$.

After neutralization, samples were diluted 1:100 in sterile water. Quantification of viral DNA in these solutions was carried out by real-time qPCR with an NS1-specific TaqMan ${ }^{\mathrm{TM}}$ probe (from Applied Biosystems, Thermo Fisher Scientific), according to previously published procedures [31].

\subsection{Cell Viability and Cell Death Assessment}

Proliferation of bone tumor cells was tested in a 96-well plate format as published, using 3-(4,5-dimethylthiazol-2-yl)-2,5-diphenyltetrazolium bromide (MTT) as a test reagent (from Sigma-Aldrich ${ }^{\circledR}$, Inc., St. Louis, MO, USA) [39]. To assess the viability of osteosarcoma cell lines, cells were seeded at 2500 cells per well and the assays were performed on days 3 and 6 post-infection. For the MTT tests pertaining to the positive control cell line (WAC-2 neuroblastoma cells), 1000 cells per well were seeded and MTT-tests were performed on days 3 and 6 post-infection. To determine the viability of primary osteoblasts and fibroblasts on day 7 after infection, cells were seeded into 96-well plates at 2500 cells per well. $12 \mathrm{~h}$ after cell seeding, the medium was removed and virus inoculum or buffer was added to the cells in $50 \mu \mathrm{L}$ serum-free medium at the indicated MOI. Two hours after infection, $50 \mu \mathrm{L}$ culture medium supplemented with $20 \%$ FCS was added in order to achieve culture conditions appropriate for the periods mentioned above. At the end of the infection period, cells were incubated for $1 \mathrm{~h}$ with $0.5 \mu \mathrm{g} / \mathrm{mL}$ MTT solution. After removing the solution, the cells were allowed to dry and isopropanol was added at $100 \mu \mathrm{L}$ per well. Absorbance values were 
photometrically determined at $570 \mathrm{~nm}$ with a Multiscan Plus ${ }^{\mathrm{TM}}$ Microplate Reader (from Titertek Instruments, Huntsville, AL, USA).

Cell lysis was determined by the amount of lactate dehydrogenase (LDH) released into the culture medium. For this, the Cytotox 96 cytotoxicity assay kit ${ }^{\mathrm{TM}}$ (from Promega, Mannheim, Germany) was used according to the manufacturer's instructions. The absorbance at $490 \mathrm{~nm}$ of red formazan generated by an LDH-catalyzed reaction was measured with the Multiscan Plus ${ }^{\mathrm{TM}}$ Microplate Reader. Both cell viability tests and cell lysis assays were carried out in five replicates. The median lethal dose (LD50) of input virus was defined as the MOI at which cell viablitiy was reduced by at least $50 \%$ (as determined by the MTT test) and cell lysis reached at least 50\% (as determined in the LDH release assay).

\subsection{Flow Cytometric Characterization of the Cell-Cycle Distribution of Cells and of the Sub-G1 Apoptotic Cell Population}

Osteosarcoma cells or WAC-2 neuroblastoma cells were seeded in triplicate (respectively, at $2 \times 10^{5}$ or $1 \times 10^{6}$ cells per 10-cm-diameter dish), infected with H-1PV (1 PFU/cell), and cultured for up to $120 \mathrm{~h}$. Control (mock-infected) cells were harvested at the corresponding time points. Cells were washed twice with PBS and then fixed with $0.7 \mathrm{~mL}$ ice-cold $100 \%$ ethanol and $0.2 \mathrm{~mL}$ PBS. Fixed cells were stored at $-20^{\circ} \mathrm{C}$. For analysis, the cells were pelleted for $10 \mathrm{~min}$ at $400 \times g$ and $4{ }^{\circ} \mathrm{C}$ and washed twice with PBS. Cell pellets were resuspended in PBS containing $100 \mathrm{mg} / \mathrm{mL}$ RNase H and $5 \mu \mathrm{g} / \mathrm{mL}$ propidium iodide (Sigma-Aldrich Inc., St. Louis, MO, USA). The stained cells were filtered through a 41- $\mu \mathrm{m}$ nylon mesh, incubated on ice for $1 \mathrm{~h}$ in the dark, and their DNA content was measured on a FACSort flow cytometer (Becton, Dickinson and Company, Franklin Lakes, NJ, USA). A minimum of 10,000 events were recorded and analyzed with the Cell-Quest ${ }^{\mathrm{TM}}$ software (from Becton, Dickinson, NJ, USA). Differences in cell cycle distribution were tested for statistical significance by a two-sided Student's $t$-test.

\section{Results}

\subsection{Protoparvovirus H-1PV Enters and Transduces Non-Transformed and Transformed Mesenchymal Cells}

We first determined whether H-1PV could enter mesenchymal cells and express its viral genes. For this, cultures of a panel of cells were inoculated with a recombinant replication-deficient H-1PV-based vector expressing EGFP (Chi-hH1/EGFP). To investigate whether parvovirus infection of mesenchymal cells depended on the transformation status of the cells or on an osteogenic-lineage-specific differentiation pattern, viral infectivity was compared in primary human osteoblasts, non-transformed neonatal foreskin fibroblasts, and three osteosarcoma cell lines. The neuroblastoma cell line WAC-2, a SH-EP subclone stably transfected with the MYCN gene, was used as a positive control [39]. Cells were infected with Chi-hH1/EGFP at an MOI of 0,1, 10, or 50 replication units (RU) per cell, and EGFP-positive cells were counted manually under a fluorescence microscope at 24-h intervals for 3 days after infection (Figure 1). In the case of primary osteoblasts and fibroblasts, the observation period was extended to $192 \mathrm{~h}$ post-infection (Figure 1), as these non-transformed mesenchymal cells displayed no relevant cytopathic effect over this timespan. In each cell culture the intensity of the fluorescence increased over time in the infected cells. The higher the efficacy of viral entry and transduction was, the earlier this maximum level of EGFP expression has been reached. 

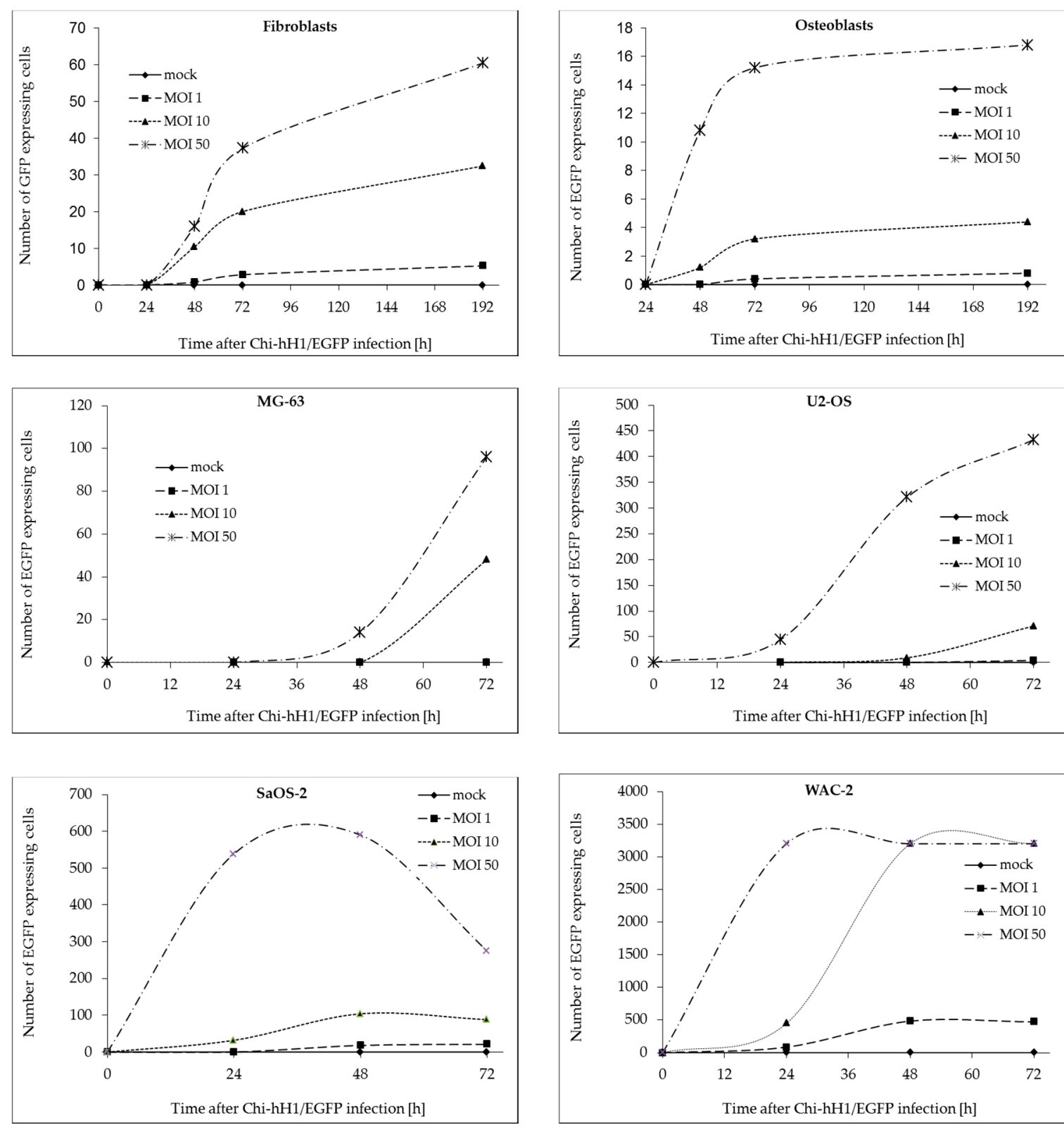

Figure 1. Susceptibility of bone tumor cells to H-1PV infection. Primary human osteoblasts and fibroblasts, the human osteosarcoma cell lines U-2 OS, SaOS-2, and MG-63, and the human neuroblastoma cell line WAC-2 were infected with Chi-hH1/EGFP at a multiplicity of infection (MOI) of $0,1,10$, or $50 \mathrm{RU} /$ cell. Green florescent cells were counted at different times post-infection. Counting was done manually in a pool of 4000 (for cell lines) or 10,000 cells (for primary osteoblasts or fibroblasts) per well.

In WAC-2 viral gene and transgene expression reached its maximum within $24 \mathrm{~h}$ after infection, whereas in SaOS-2 $48 \mathrm{~h}$ and in the other osteosarcoma cell lines $72 \mathrm{~h}$ are necessary to reach maximum EGFP expression levels.

As expected, the non-transformed cells showed low permissiveness towards H-1PV infection [23]. At the highest MOI tested (50 RU/cell), fluorescence was observed in only $4 \%$ of primary osteoblasts and 15\% of human neonatal fibroblasts. EGFP expression persisted throughout the 8-day post-infection observation period (Figure 1, upper panel). It is worth noting that upon infection with $\mathrm{H}-1 \mathrm{PV}$ at MOI $\geq 50 \mathrm{PFU} /$ cell, proliferation of human foreskin fibroblasts was inhibited (Figure S1), and their lysis induced (Figure 2). The effect of the virus on primary human osteoblast integrity 
and viability was likewise marginal (Figure S1). In other words, virus-induced cytotoxicity towards non-transformed mesenchymal cells was limited. The different osteosarcoma cell lines also showed differences in susceptibility to H-1PV infection. MG-63 displayed the lowest susceptibility, with only $2.5 \%$ EGFP-expressing cells $72 \mathrm{~h}$ after infection at $\mathrm{MOI}=50 \mathrm{RU} /$ cell. Under the same conditions, the percentage of fluorescent cells was $10 \%$ for the U2-OS cell line and $15 \%$ for the SaOS-2 cell line. In the WAC- 2 cell line used as positive control, the proportion of fluorescent cells after $72 \mathrm{~h}$ was $80 \%$ after infection at MOI $=10 \mathrm{RU} /$ cell.

(A)
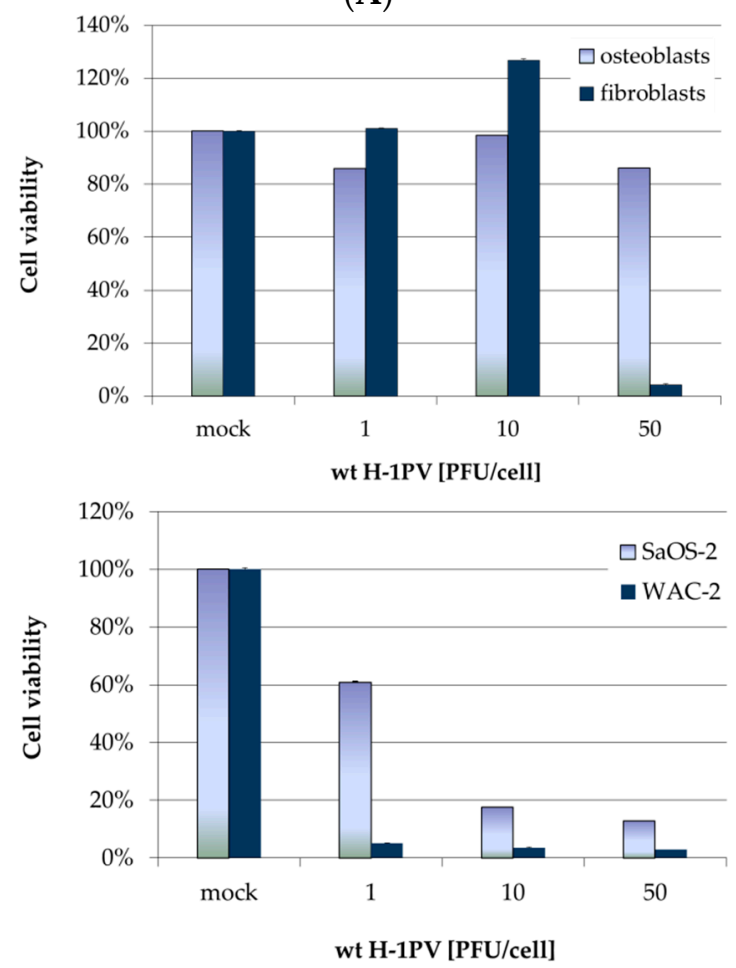

(B)
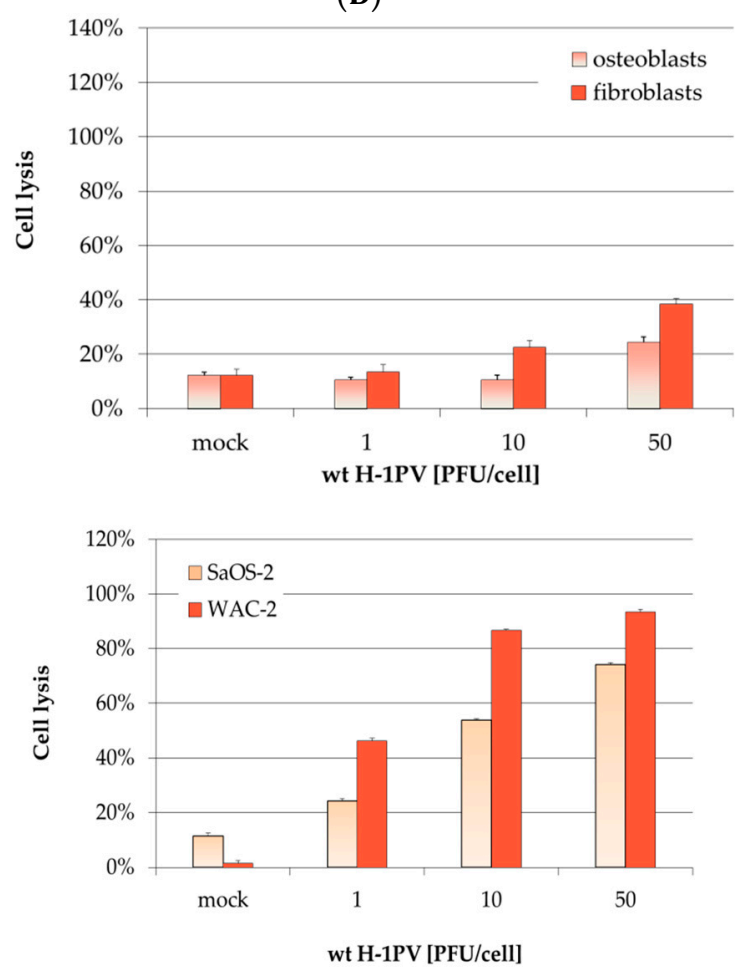

Figure 2. Innocuousness of wild-type H-1PV towards non-transformed mesenchymal cells. (A) 3-(4,5-dimethylthiazol-2-yl)-2,5-diphenyltetrazolium bromide (MTT) test for cell viability quantification, performed 7 days after H-1PV infection. Metabolic activity values were normalized to mock-treated control cells. Bars represent means of eight independent experiments, and the corresponding error bars represent standard errors of the mean (SEM); (B) lactate dehydrogenase (LDH)-release assays for quantifying H-1PV-induced cell lysis. LDH release was assayed three days after H-1PV infection. LDH activity in supernatants was normalized with respect to complete lysis with Triton. SaOS-2 and WAC-2 (lower panel) were used as positive controls.

The effects of H-1PV infection in non-transformed mesenchymal cells were further characterized and quantified as regards cell viability (MTT tests) and virus-induced cell lysis (LDH-release assays) shown in Figure 2. After infection with high titers of virus, neonatal fibroblasts appeared more susceptible to virus-induced cytotoxicity than osteoblasts (Figure 2, right upper panel). When the former cells were infected with H-1PV at an MOI of $50 \mathrm{PFU} /$ cell, a highly significant reduction in mitochondrial metabolism was observed (Figure 2, left upper panel). This reduction in cell viability correlated with lysis of a significant number of neonatal fibroblasts. Osteoblasts, on the other hand, showed no substantial reduction of metabolic activity for up to 7 days post-infection, even after infection at an MOI of $50 \mathrm{PFU} /$ cell. A 10\% decrease in metabolic activity was observed, accompanied by a corresponding increase in cell lysis. In contrast, SaOS-2 and WAC-2 cells showed a clear, dose-dependent cytopathic effect within $72 \mathrm{~h}$ after infection (Figure 2, lower panel). 


\subsection{H-1PV Infection of Non-Transformed Mesenchymal Cells Induces Antiproliferative Effects and Toxicity} Only at High Virus Doses

As mentioned above, no cytopathic effects were observed in primary osteoblasts or neonatal foreskin fibroblasts after infection with Chi-hH1/EGFP at an MOI up to $50 \mathrm{RU} /$ cell. To determine the therapeutic window of wild-type H-1PV application to mesenchymal cells, cells were infected with this virus at increasing MOI. Although no cytopathic effect was observed after infection of osteoblasts or fibroblasts with low doses of H-1PV, the number of cells was found to decrease within 7 days after infection at MOI = $50 \mathrm{PFU} /$ cell or higher. These cytomorphological findings indicate that at high MOI, wild-type H-1PV infection does have a significant cytotoxic effect on these non-transformed cells (Figure S1). In a clinical setting, however, such high MOIs are unlikely to be reached in replication-deficient, non-transformed tissues, if not caused by local, iatrogenic infections.

\subsection{H-1PV Viral Protein Expression Induces Cell Cycle Arrest in G2/M in Osteosarcoma Cells}

Expression of the nonstructural protein NS1 encoded by wild-type H-1PV was analyzed in a time course experiment by western blotting (Figure 3). In all osteosarcoma cell lines, NS1 accumulation became detectable between 12 and $24 \mathrm{~h}$ after H-1PV infection, reached a maximum after $48 \mathrm{~h}$, and started to decrease $120 \mathrm{~h}$ post-infection in U2-OS cells (Figure 3, left part) or $72 \mathrm{~h}$ post-infection in SaOS-2 cells (Figure 3, right part). In all cases, the decrease was slow until about $80 \%$ of the cells in the culture had died. For each cell line, the time point at which a significant decrease in NS1 expression was detected correlated with the observation of distinct cytomorphological changes indicating a cytopathic effect of H-1PV in the cell line considered (Figure 4 and Figure S2).

U2-OS

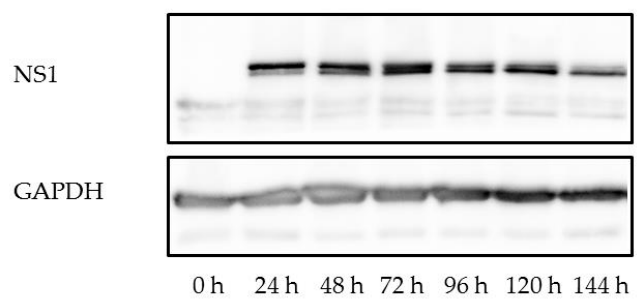

SaOS-2

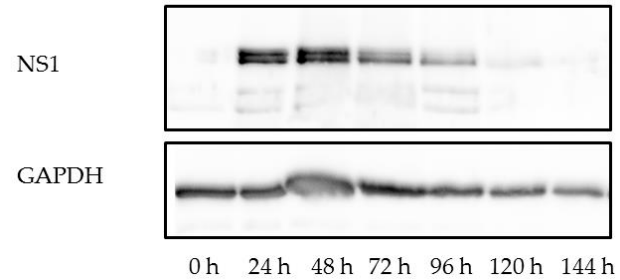

Figure 3. Western blot analysis of NS1 in H-1PV-infected osteosarcoma cells. Osteosarcoma cells were either mock-treated or infected with wild-type H-1PV (MOI: 1 plaque-forming units (PFU) per cell). Cell lysates from cultures collected at the indicated times were processed for western blotting with NS1-specific primary antiserum and horseradish-peroxidase-conjugated secondary antibodies. Blots were revealed by chemiluminescence. In H-1PV-infected cell lysates, two NS1-specific bands of approximately $60 \mathrm{kDa}$ were detected. GAPDH was used as loading control. Results for SaOS-2 and U2-OS are shown as examples.

Flow cytometric analyses revealed, $96 \mathrm{~h}$ after H-1PV infection, a significant (10-25\%) decrease in cells in G1 in all osteosarcoma cell lines tested. Simultaneously, a significantly higher proportion of cells in G2/M (10-30\%) were observed in each cell line, as compared to mock-infected cells. H-1PV infection did not increase the percentage of apoptotic cells (subG1 fraction) in the osteosarcoma cell lines analyzed. The capacity of the H-1PV NS1 protein to disrupt the cell cycle has been described in an NS1-inducible stable HEK293-derived cell line [40]. We next investigated the effects of prolonged NS1 expression on the cell cycle distribution of osteosarcoma cells. After infection, cells were collected at 24-h intervals over a 96-h period, as described for the western blot analysis. Cell cycle analyses were performed at each time point. Percentages of cells in the different phases of the cell cycle are represented in Figure 5. 

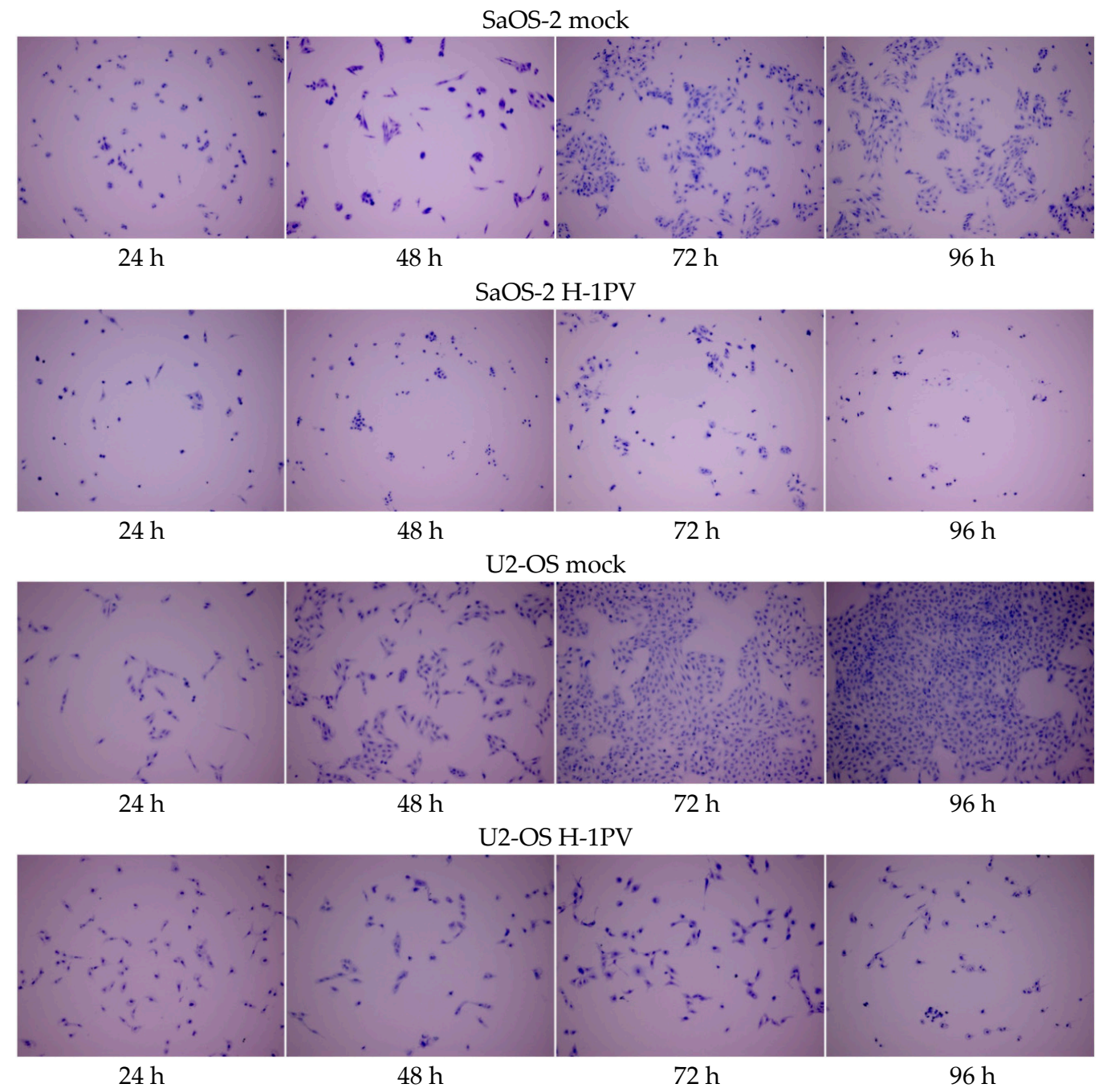

Figure 4. H-1PV infection induces antiproliferative and cytotoxic effects in osteosarcoma cell lines. Microscope images of osteosarcoma cells stained with crystal violet at 24-h intervals for up to $96 \mathrm{~h}$ after infection with 1 PFU wild-type H-1PV per cell. Upper panels: mock-infected cells. Magnification: $100 \times$.
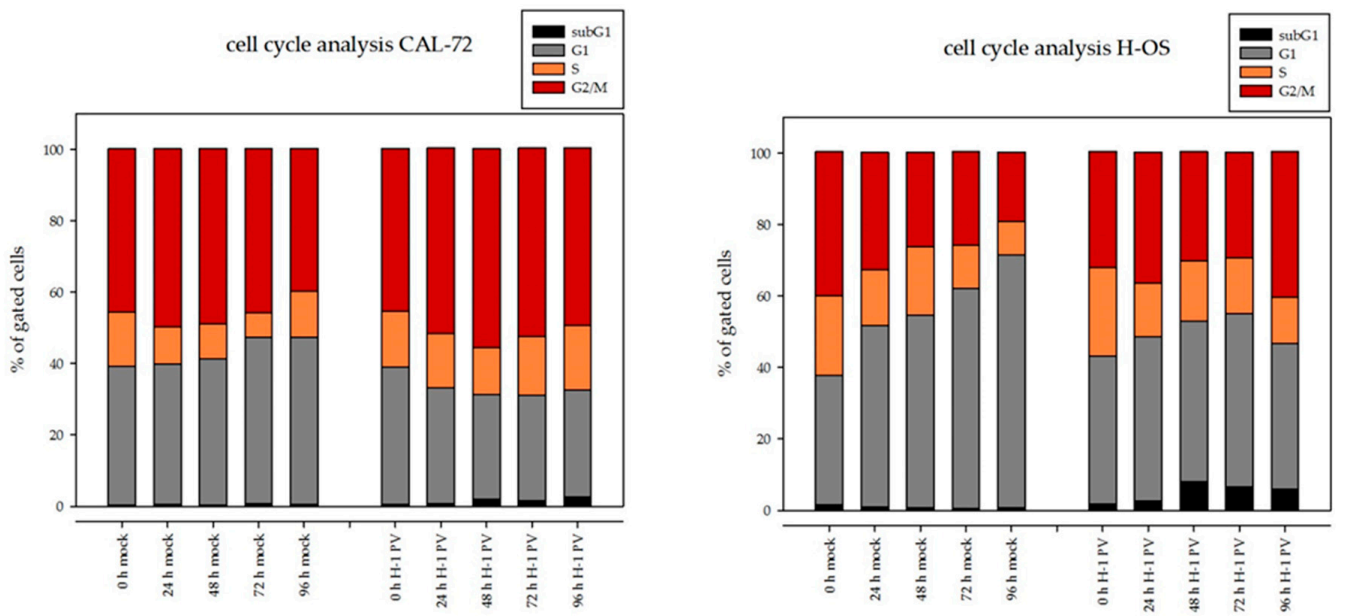

Figure 5. Cont. 

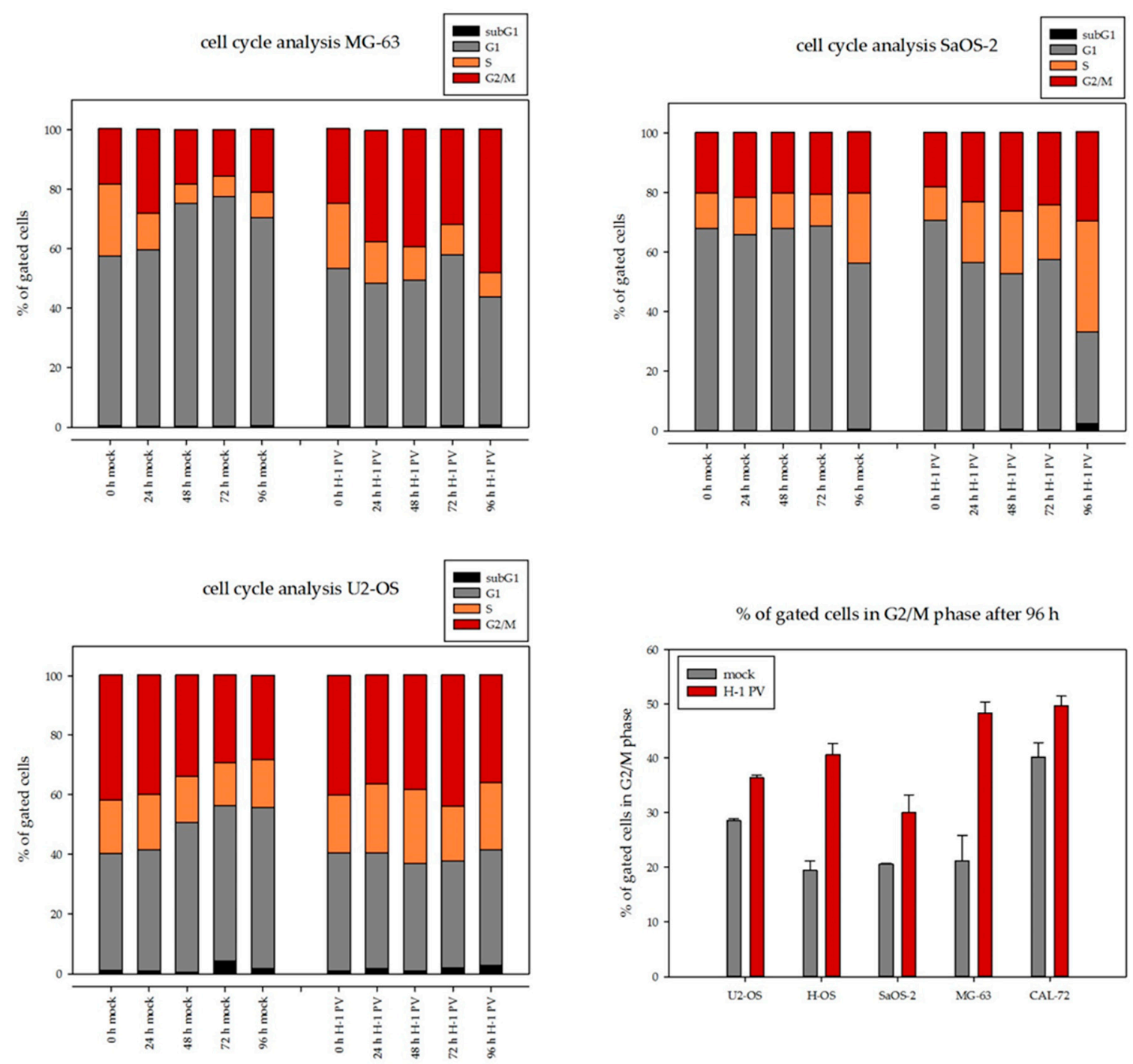

Figure 5. H-1PV infection induces G2/M arrest in osteosarcoma cells. FACSort flow cytometer analysis after propidium iodide staining. Acquisition of at least 10,000 events for each flow cytometric analysis allowed calculating the percentage of cells in G1, S, and G2/M at each time point (left panel). An excerpt focusing on mock- and H-1PV-infected cells arrested in G2/M at the time of infection and $96 \mathrm{~h}$ thereafter is provided in the right lower panel. Increase of cells in G2/M in H-1PV infected cells in comparison to mock-treated cells is highly significant $(p>0.001$, two-sided Student's $t$-test) for each cell line.

\subsection{Osteosarcoma Cells Undergo Lytic H-1PV Infection}

Virus-induced cytopathic effects (CPE) on osteosarcoma cells were visualized by crystal violet staining of the cells at different time points after $\mathrm{H}-1 \mathrm{PV}$ infection. They were observed in all established osteosarcoma cell lines, and the number of cells affected increased over time. In CAL-72, H-OS, SaOS-2, and U2-OS cells, H-1PV-induced cytomorphological changes appeared $48 \mathrm{~h}$ after infection. In all osteosarcoma cell lines, $\mathrm{H}-1 \mathrm{PV}$ infection reduced cell proliferation and induced significant cell death, as shown for SaOS-2 and U2-OS (Figure 4) and as documented in Figure S2 for the CAL72, $\mathrm{H}-\mathrm{OS}$, and MG-63 cell lines. In MG-63 cells, the onset of virus-induced CPE became obvious $72 \mathrm{~h}$ after infection. 


\subsection{In Osteosarcoma Cells, H-1PV Infection Does Not Lead to Efficient Production of Infectious Viral Progeny}

The capacity of the autonomous protoparvovirus H-1PV to replicate in malignant cells has been widely described $[23,28]$. Yet human malignant cells of different origins are known to vary in their capacity to produce fully infectious viral progeny, and one might expect the antitumor efficacy of H-1PV to increase with the ability of the infected cells to produce and spread progeny virions. Therefore, virus replication was determined in our panel of osteosarcoma cell lines. In time-course experiments performed as described in the Materials and Methods section, the increase in full particles and the release of infectious viral particles into the supernatant were quantified in each of the five established osteosarcoma cell lines.

(A)

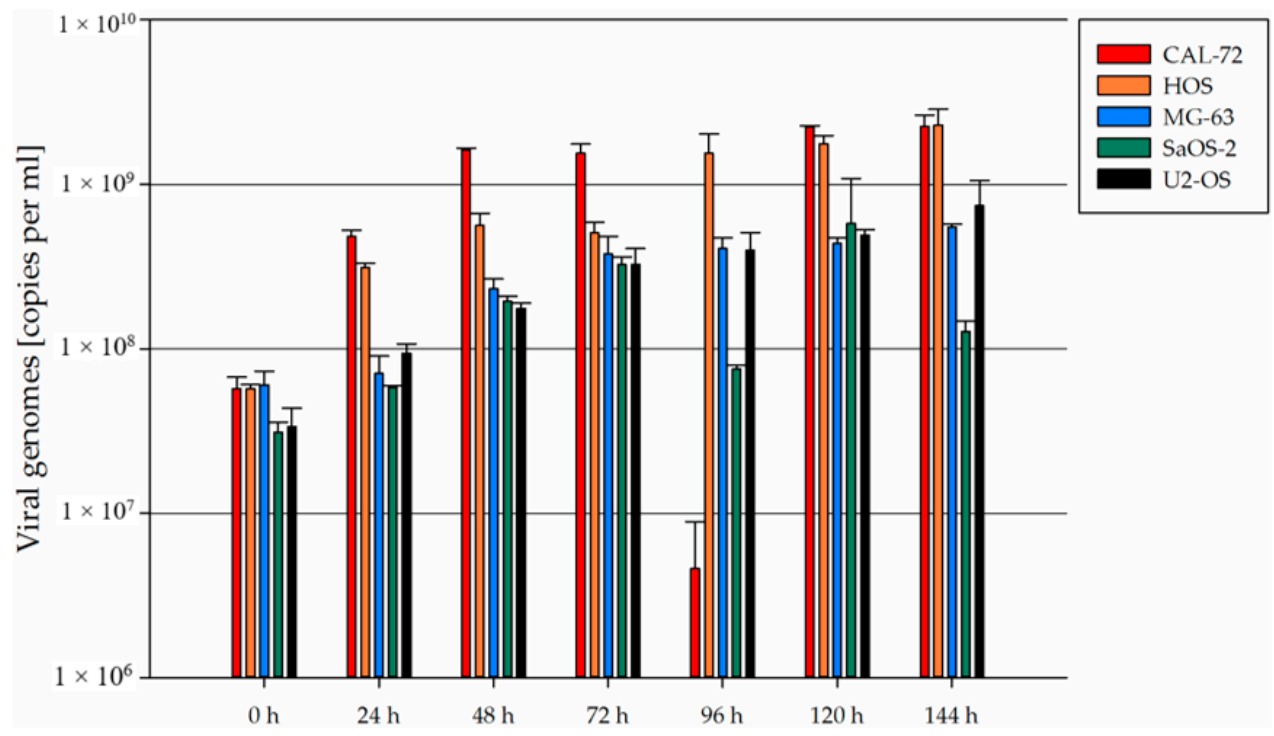

(B)

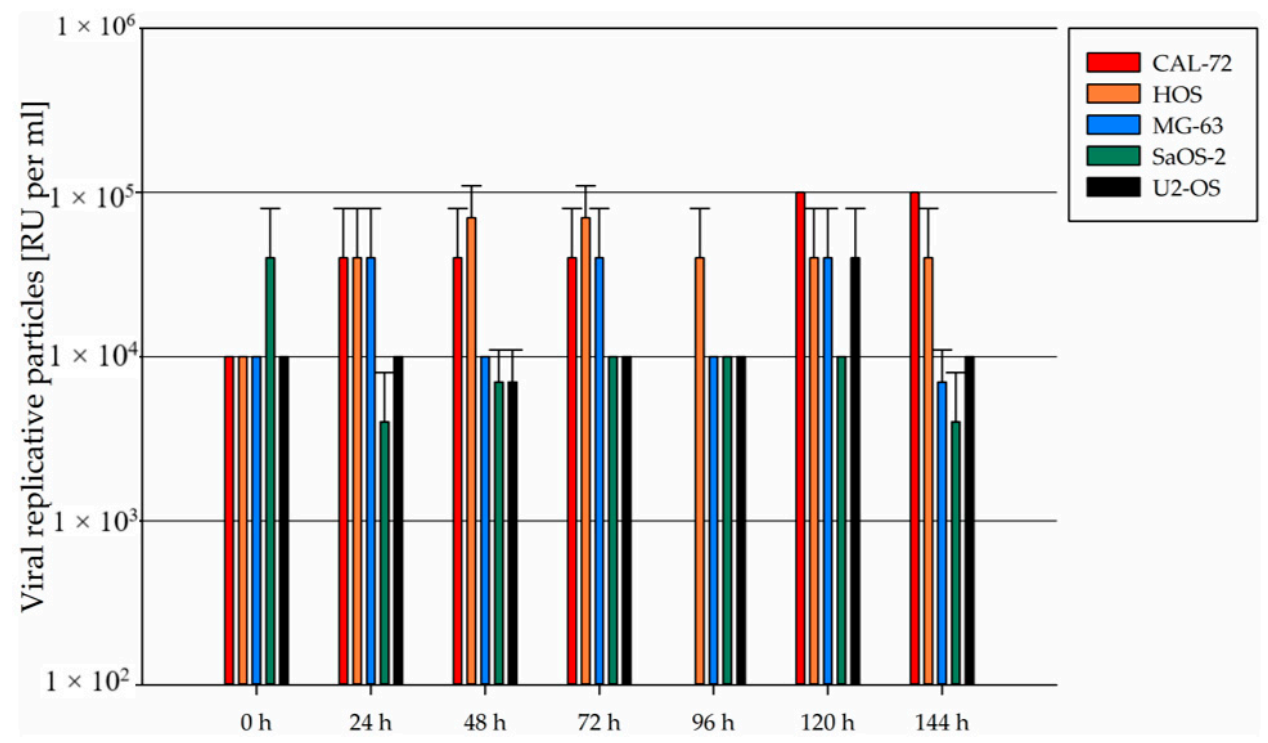

Figure 6. The efficiency of wtH-1PV replication in osteosarcoma cells is limited. Cells were infected with one infectious particle per cell (PFU/cell) and cell supernatants were collected at the indicated times. (A) The number of viral genome copies released was determined into the cell culture medium in triplicate by quantitative polymerase chain reaction (qPCR) (copies $/ \mathrm{mL}$ ), and means are shown. Error bars represent SEM (upper panel); (B) titers of infectious particles $(\mathrm{RU} / \mathrm{mL})$ were determined by infecting NBK324K cells with serial dilutions of the cell culture supernatant and by dot blot detection of viral DNA $72 \mathrm{~h}$ after infection. Error bars represent SEM (lower panel). 
Compared to the input virus remaining in the cell culture medium $(0 \mathrm{~h})$, the number of viral DNA copies increased 5- to 10-fold in all five osteosarcoma cell lines, as determined by quantitative PCR (Figure 6, upper panel). Accordingly, the titer of full infectious viral particles did not increase by more than one log-step over the $144 \mathrm{~h}$ following infection in any of the five osteosarcoma cell lines tested (Figure 6, lower panel).

\subsection{Wild-Type H-1PV Is More Cytotoxic Towards Osteosarcoma Cells Than H-1PV-Derived Fitness Mutants}

Given the limited replicative capacity of wild-type H-1PV in osteosarcoma cells, we tested whether higher cytotoxicity might be achieved after infecting osteosarcoma cells with one of two derived virus mutants: Del H-1PV, a virus mutant previously described to propagate more efficiently in human pancreatic cancer cells [32], and H1-DM, a virus fitness mutant carrying two point mutations in the non-structural (NS) coding gene. The cytotoxic effects on osteosarcoma cells of the two mutant viruses and of wild-type H-1PV were compared. To assess cell viability, MTT tests and quantification of metabolic activity in surviving cells were performed. To quantify virus-induced osteosarcoma cell lysis, LDH-release assays were carried out. LD50 titers of input virus were determined as described in the Materials and Methods section.

As exemplified in Figure 7 and Figure S3 and as quantitated in Table 1, Del H-1PV showed the lowest cytotoxicity in all osteosarcoma cell lines and did not induce any significant cytotoxic effects in two cell lines, MG-63 and U2-OS, within the range of doses tested. In CAL-72, for example, the LD50 for Del H-1PV was 10 times as high as for DM H-1PV and 20 times as high as for wild-type H-1PV. For DM H-1PV, the LD50 values determined ranged from 1 PFU per cell in CAL-72 to 25 PFU per cell in MG-63. In other words, the dose of input virus required to induce lytic infection of at least $50 \%$ of the osteosarcoma cells was the same (in U2-OS) to 5 times as high (in H-OS) with DM H-1PV as with wild-type $\mathrm{H}-1 \mathrm{PV}$. In these experiments, wild-type $\mathrm{H}-1 \mathrm{PV}$ thus induced osteosarcoma cell death at a lower dose of input virus than did either of the two mutants tested.

Table 1. LD50 titers of wild-type H-1PV and mutant virus strains in pediatric osteosarcoma cell lines.

\begin{tabular}{cccc}
\hline Cell Culture & Del H-1PV & DM H-1PV & wt H-1PV \\
\hline CAL-72 & 10 & 1 & 0.5 \\
H-OS & 5 & 5 & 1 \\
MG-63 & n. r. & 25 & 10 \\
SaOS-2 & $>10$ & 10 & 5 \\
U2-OS & n. r. & 5 & 5 \\
\hline
\end{tabular}

LD50 of input virus as determined on day 6 after infection with wild-type H-1PV or a mutant virus. Cytotoxic effects induced by infection with wild-type H-1PV, the DM H-1PV double mutant, or the Del H-1PV mutant (having a deletion in NS) were quantified by assaying cell viability and cell lysis as described in the Materials and Methods section. Briefly, 6 days after infection with a viral strain at increasing MOI, MTT tests and LDH-release assays were performed in parallel. LD50 of input virus are given in plaque-forming units per cell. If the LD50 of the tested virus strain was not reached under the conditions analyzed, "n. r." is indicated. 

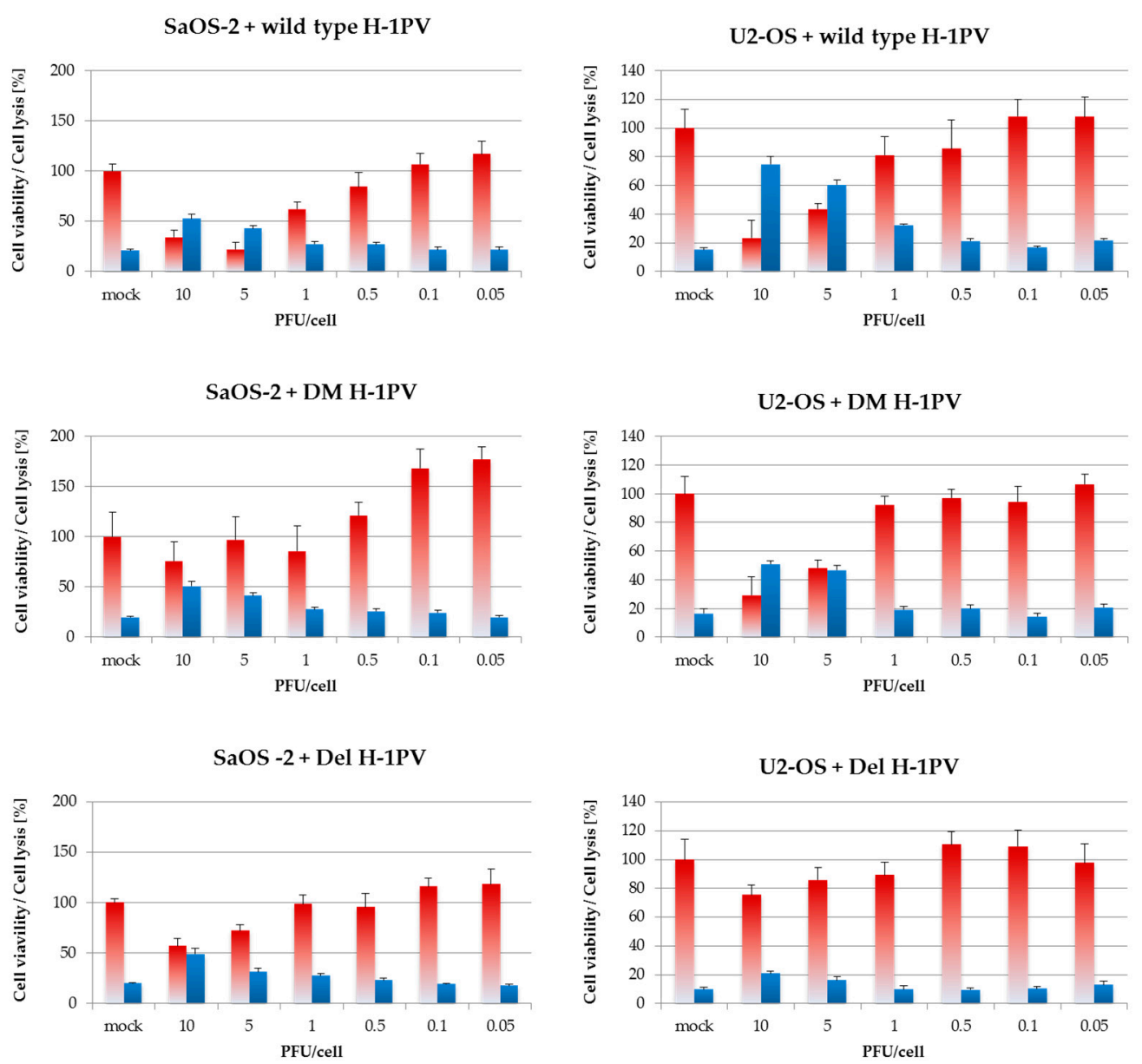

Figure 7. Six days after infection, wild-type H-1PV shows stronger toxicity towards osteosarcoma cells than mutant viruses. Cells were infected with increasing titers of wild-type H-1PV, Del H-1PV, or double-mutant H1-DM. Six days after infection, cytotoxicity testing was performed in 96-well plates in simultaneous MTT tests and LDH-release assays. Red and blue bars represent means of eight independent experiments and error bars represent standard errors of the mean (SEM). Cell viability is indicated in blue and cell lysis in red.

\section{Discussion}

\subsection{Safety Profile of Wild-Type H-1PV in Human Mesenchymal Cells}

The protoparvoviruses, first described as $\mathrm{H}$ viruses, induce a characteristic pathogenesis in some rodent species. Transplacental infection or direct inoculation of $\mathrm{H}$ viruses into newborn hamsters affects replicating cells of the developing bone. Infection of these cells results in dwarfism and malformation of teeth and bones in surviving hamsters. This characteristic phenotype has been described as osteolytic syndrome [41]. Inoculation of $\mathrm{H}-1 \mathrm{PV}$ within the first $48 \mathrm{~h}$ postpartum most consistently induces the complete phenotype. Animals infected at a later time show fewer signs the older they are at the time of infection. $\mathrm{H}-1 \mathrm{dr}$, the first variant $\mathrm{H}-1$ virus described to have an increased capacity to replicate in human cells, also shows this specific pathogenicity in newborn hamsters [42]. Signs of an osteolytic syndrome have never been reported after infection of adult hamsters by rodent parvoviruses $[26,41]$. In rats, the natural host of $\mathrm{H}-1 \mathrm{PV}$, virus-induced pathogenicity shows the same age-dependency: in fetuses and neonates, H-1PV infection can be pathogenic or even lethal, whereas in adult animals it remains clinically unapparent [26]. These observations have been taken as evidence that parvovirus pathogenicity is restricted to proliferating and differentiating mesenchymal tissues. 
Therefore, prior to a clinical application in child or adolescent sarcoma patients, it was important to evaluate the cytotoxicity of H-1PV very carefully in primary mesenchymal cells of pediatric origin. Our results show that $\mathrm{H}-1 \mathrm{PV}$ can enter non-transformed mesenchymal human cells, such as osteoblasts and fibroblasts. Yet in our study, the only non-transformed cells to be transduced were neonatal human fibroblasts, and only after infection at high MOI they did show a clear cytopathic effect. Such high viral titers are unlikely under conditions other than local infections of neighboring replication-competent cells or local virus applications in the course of treatment. The virus dose range at which H-1PV is non-toxic towards non-transformed mesenchymal cells is comparable to the dose range previously identified as innocuous towards non-transformed infant neuroepithelial cells [39].

\subsection{Osteosarcoma Cells Are Semi-Permissive to Wild Type H-1PV Infection}

Oncolytic effects induced by H-1PV have been observed in a variety of rodent and human cancer cells [26]. A previous publication has described a parvovirus-H1-derived vector expressing Apoptin to have a greater capacity to induce apoptosis than wild-type H-1PV [43]. In proof-of-concept experiments in which wild-type H-1PV was applied to a set of four cell lines, including two osteosarcoma cell lines, first indications of the capacity of wild-type H-1PV to induce cytopathic effects and subsequent cell death were obtained [43].

As a first step in assessing the therapeutic potential of H-1PV for pediatric and adolescent osteosarcoma, the aim of the present study was to assess the capacity of H-1PV to replicate in osteosarcoma cell lines and to perform a systematic quantification in vitro of H-1PV-induced effects on the cell cycle and cell viability. In the five pediatric osteosarcoma cell lines analyzed, accumulation of the major parvoviral cytotoxic protein NS1 started during the first 12-24 h after infection with wild-type $\mathrm{H}-1 \mathrm{PV}$, and the amount accumulated remained unaltered for at least $120 \mathrm{~h}$. NS1 has been shown to be sufficient to induce G2-arrest in HEK-293 and HeLa cells. In these cells, G2 arrest leads to activation of caspases 9 and 3 which results in apoptotic cell death [40].

In all osteosarcoma cell lines, a significant increase in the proportion of H-1PV-infected cells arrested in G2/M was observed over time. The observed virus-induced disturbances of the cell cycle were accompanied by distinct cytomorphological changes in all osteosarcoma cell lines. Eventually, osteosarcoma cell proliferation was inhibited and cell death occurred. In contrast to findings on pediatric neuroectodermal tumor cells $[39,44]$, apoptotic DNA fragmentation does not appear to play a key role in this process in osteosarcoma cells, but the molecular mechanisms by which NS1 expression induces cell death in osteosarcoma remain to be further characterized.

Efficient spreading of an oncolytic virus throughout a tumor mass requires the capacity to induce secondary rounds of infection. Essential prerequisites to this process are efficient virus replication and viral egress. Although wild-type H-1PV has been characterized as a self-replicating oncolytic virus, its replication efficiency varies widely among different tumor entities [26]. We therefore quantified the virus production capacity of the cell lines studied. Over a seven-day period post-infection, only two cell lines showed an increase in infectious particle titer, and this increase was limited. This poor viral replication efficiency may limit the therapeutic efficacy of wild-type H-1PV in osteosarcoma patients.

\subsection{Fitness Mutants Do Not Show Increased Cytotoxicity Towards Osteosarcoma Cells In Vitro}

Two mutant protoparvovirus H-1 strains, Del H-1PV [32] and DM H-1 [45], have been described as more efficient than wild-type $\mathrm{H}-1 \mathrm{PV}$ in progeny virus release and propagation in human cancer cell cultures. We have applied these strains to a panel of osteosarcoma cell lines characterized as semi-permissive to wild-type H-1PV infection, and have estimated their capacity to induce sustained cytotoxic effects. Both primary and secondary cytotoxic effects are observed after six days of in vitro exposure to low titers of input virus, depending on the efficiency of virus replication and propagation in the transformed host cell population through successive rounds of infection. The first fitness mutant derived from standard H-1PV, H-1 dr, was described in 1995 [42]. H-1 dr is a naturally occurring variant with a higher efficiency of spreading in permissive human cells. This variant is characterized 
by specific sequence alterations, including an in-frame deletion of codons 39 to 41 and a tandem duplication of $58 \mathrm{nt}$ close to the right-hand origin of replication. The deletion in the region encoding NS1 and NS2 results, upon translation, in truncated viral proteins [42]. Del H-1 was derived from the existing molecular standard H-1PV clone by deleting nucleotides 2022 to 2135 [32], so as to mimic the 114-nt deletion occurring naturally in H-1dr. The truncated NS1 and NS2 proteins are hypothesized to play a key role in the greater capacity of Del H-1 progeny virions to be exported from the nucleus and to egress from the host cell, and hence in the increased antineoplastic efficacy of the mutant virus in two pancreatic cancer xenograft models [42].

In our comparative analysis of viral cytotoxicity towards the panel of osteosarcoma cell lines, focusing on the wild-type virus and the above-mentioned variants, Del H-1 required the highest dose of input virus to cause at least $50 \%$ of the cell population to die. In two osteosarcoma cell lines, Del H-1PV was unable to induce any significant cytotoxic effect, even at the highest MOI applied. With the fitness mutant H-1 DM, the LD 50 of input virus was reached in all five osteosarcoma cell lines. It ranged from 1 PFU per cell in the most susceptible cell line (CAL-72) to 50 PFU per cell in the least susceptible cell line (MG-63). The highest efficacy against semi-permissive pediatric osteosarcoma cells was observed with the standard wild-type H-1PV: in all five osteosarcoma cell lines tested, the LD50 titer of input wild-type H-1PV ranged from 0.5 to $10 \mathrm{PFU} /$ cell. These unexpected in vitro data led us to speculate that the previously described higher replication and spreading efficiency of the mutant viruses Del H-1PV and H-1 DM might be restricted to virus-replication-competent host cells. Our experiments performed to define the therapeutic window for wild-type H-1PV showed it to be innocuous to non-transformed mesenchymal cells at MOIs below $50 \mathrm{PFU} /$ cell. Accordingly, the cytotoxic effects of standard H-1PV measured in osteosarcoma cell culture models correspond to a therapeutic index of 5 to 100 .

The present study is part of a strategy aiming to define pediatric indications for first applications of H-1PV in clinical trials testing the therapeutic efficacy of H-1-based parvovirotherapy. We show that osteosarcoma is a potential parvovirus-responsive pediatric tumor entity, as all the human sarcoma cells tested proved sensitive to the cytopathic effects of wild-type H-1PV. To take full therapeutic advantage of the application of a self-replicative oncolytic virus, it may be desirable to select target tumors that show some degree of competence for virus multiplication and propagation. Our data show that human osteosarcoma cells are heterogeneous in this regard and fail to achieve high yields of progeny H-1PV production. In an attempt to overcome this limitation, we have tested two H-1PV mutants reported to replicate more efficiently than H-1PV in other human cancer cell models, but these mutants failed to surpass the wild-type parental virus in osteosarcoma cells. This illustrates the host-cell-type specificity of their enhanced infectivity.

\section{Conclusions}

The present in vitro study represents a systematic preclinical analysis, in pediatric and adolescent osteosarcoma cell culture models, of the oncoselectivity and oncolytic efficacy of the wild-type protoparvovirus H-1PV and of its mutant derivatives Del H-1PV and H-1DM. We show that, in contrast to observed effects on other malignant diseases, the wild-type protoparvovirus H-1PV eliminates osteosarcoma cells more effectively than the two mutant viruses. Future steps in the preclinical validation of H-1PV for osteosarcoma treatment will include, besides adapting the virus for enhanced production, combining it with other cancer therapeutics in the framework of multimodal treatment strategies. Systematic preclinical testing should pave the way towards well-designed clinical trials evaluating oncolytic parvovirotherapy in child, adolescent, and young adult osteosarcoma patients.

Supplementary Materials: Supplementary materials can be found at www.mdpi.com/1999-4915/9/10/301/s1.

Acknowledgments: We thank Michèle Klein and Nathalie Salomé for providing the polyclonal antisera against NS-1. We also gratefully acknowledge the excellent technical assistance of Franziska Schlund and Alexandra Stroh-Dege in cell culture and infection experiments. Funding of the M.Sc. studies of Zoltán Kis by the Dinu Patriciu Foundation (through an Open Horizons scholarship) is also gratefully acknowledged. The present 
work was financially supported by the German Cancer Research Center and by a research grant from ORYX $\mathrm{GmbH} \& \mathrm{Co} ., \mathrm{KG}$ to Jeannine Lacroix and Jean Rommelaere.

Author Contributions: Carsten Geiss, Zoltán Kis, Christiane Dinsart, and Jeannine Lacroix conceived and designed the experiments; Carsten Geiss and Zoltán Kis performed most experiments; Monika Frank-Stöhr contributed the technical expertise and analysis of the raw data to the cell cycle analysis; Barbara Leuchs produced the standard H-1PV virus and performed all virus titrations; Carsten Geiss, Zoltán Kis, and Jeannine Lacroix analyzed the data; Christiane Dinsart designed and produced mutant and recombinant H-1PV viruses; Zoltán Kis prepared a preliminary draft in 2013; Jeannine Lacroix wrote the paper in its present form; and Jörg R. Schlehofer, Christiane Dinsart and Jean Rommelaere provided conceptual ideas for the present study or contributed substantial corrections.

Conflicts of Interest: The authors declare no conflict of interest. The funding sponsors had no role in the design of the study, in the collection, analysis, or interpretation of data, in writing the manuscript, or in the decision to publish the results.

\section{References}

1. Siegel, R.L.; Miller, K.D.; Jemal, A. Cancer statistics, 2016. CA Cancer J. Clin. 2016, 66, 7-30. [CrossRef] [PubMed]

2. Ward, E.; DeSantis, C.; Robbins, A.; Kohler, B.; Jemal, A. Childhood and adolescent cancer statistics, 2014. CA Cancer J. Clin. 2014, 64, 83-103. [CrossRef] [PubMed]

3. Ottaviani, G.; Jaffe, N. The Epidemiology of Osteosarcoma. Cancer Treat Res. 2009, 152, 3-13. [PubMed]

4. Isakoff, M.S.; Bielack, S.S.; Meltzer, P.; Gorlick, R. Osteosarcoma: Current treatment and a collaborative pathway to success. J. Clin. Oncol. 2015, 33, 3029-3035. [CrossRef] [PubMed]

5. Trama, A.; Botta, L.; Foschi, R.; Ferrari, A.; Stiller, C.; Desandes, E.; Maule, M.M.; Merletti, F.; Gatta, G. Survival of European adolescents and young adults diagnosed with cancer in 2000-07: Population-based data from EUROCARE-5. Lancet Oncol. 2016, 17, 896-906. [CrossRef]

6. Anderson, M.E. Update on Survival in Osteosarcoma. Orthop. Clin. 2016, 47, 283-292. [CrossRef] [PubMed]

7. Aljubran, A.H.; Griffin, A.; Pintilie, M.; Blackstein, M. Osteosarcoma in adolescents and adults: Survival analysis with and without lung metastases. Ann. Oncol. 2009, 20, 1136-1141. [CrossRef] [PubMed]

8. Meyers, P.A.; Schwartz, C.L.; Krailo, M.D.; Healey, J.H.; Bernstein, M.L.; Betcher, D.; Ferguson, W.S.; Gebhardt, M.C.; Goorin, A.M.; Harris, M.; et al. Osteosarcoma: The addition of muramyl tripeptide to chemotherapy improves overall survival-A report from the Children's Oncology Group. J. Clin. Oncol. 2008, 26, 633-638. [CrossRef] [PubMed]

9. Kansara, M.; Teng, M.W.; Smyth, M.J.; Thomas, D.M. Translational biology of osteosarcoma. Nat. Rev. Cancer 2014, 14, 722-735. [CrossRef] [PubMed]

10. Abarrategi, A.; Tornin, J.; Martinez-Cruzado, L.; Hamilton, A.; Martinez-Campos, E.; Rodrigo, J.P.; Gonzalez, M.V.; Baldini, N.; Garcia-Castro, J.; Rodriguez, R. Osteosarcoma: Cells-of-origin, cancer stem cells, and targeted therapies. Stem Cells Int. 2016, 2016, 3631764. [CrossRef] [PubMed]

11. Russell, S.J.; Peng, K.W.; Bell, J.C. Oncolytic virotherapy. Nat. Biotechnol. 2012, 30, 658-670. [CrossRef] [PubMed]

12. Lichty, B.D.; Breitbach, C.J.; Stojdl, D.F.; Bell, J.C. Going viral with cancer immunotherapy. Nat. Rev. Cancer 2014, 14, 559-567. [CrossRef] [PubMed]

13. Burke, J.; Nieva, J.; Borad, M.J.; Breitbach, C.J. Oncolytic viruses: Perspectives on clinical development. Curr. Opin. Virol. 2015, 13, 55-60. [CrossRef] [PubMed]

14. Li, Q.X.; Liu, G.; Wong-Staal, F. Oncolytic virotherapy as a personalized cancer vaccine. Int. J. Cancer 2008, 123, 493-499. [CrossRef] [PubMed]

15. Simpson, G.R.; Relph, K.; Harrington, K.; Melcher, A.; Pandha, H. Cancer immunotherapy via combining oncolytic virotherapy with chemotherapy: Recent advances. Oncolytic Virother. 2016, 5, 1-13. [PubMed]

16. Morton, C.L.; Houghton, P.J.; Kolb, E.A.; Gorlick, R.; Reynolds, C.P.; Kang, M.H.; Maris, J.M.; Keir, S.T.; $\mathrm{Wu}, \mathrm{J}$.; Smith, M.A. Initial testing of the replication competent Seneca Valley virus (NTX-010) by the pediatric preclinical testing program. Pediatr. Blood Cancer 2010, 55, 295-303. [CrossRef] [PubMed]

17. Ketola, A.; Hinkkanen, A.; Yongabi, F.; Furu, P.; Määttä, A.M.; Liimatainen, T.; Pirinen, R.; Björn, M.; Hakkarainen, T.; Mäkinen, K.; et al. Oncolytic Semliki forest virus vector as a novel candidate against unresectable osteosarcoma. Cancer Res. 2008, 68, 8342-8350. [CrossRef] [PubMed] 
18. Witlox, A.M.; van Beusechem, V.W.; Molenaar, B.; Bras, H.; Schaap, G.R.; Alemany, R.; Curiel, D.T.; Pinedo, H.M.; Wuisman, P.I.; Gerritsen, W.R. Conditionally replicative adenovirus with tropism expanded towards integrins inhibits osteosarcoma tumor growth in vitro and in vivo. Clin. Cancer Res. 2004, 10, 61-67. [CrossRef] [PubMed]

19. Li, X.; Jung, C.; Liu, Y.H.; Bae, K.H.; Zhang, Y.P.; Zhang, H.J.; VanderPutten, D.; Jeng, M.H.; Gardner, T.A.; Kao, C. Anti-tumor efficacy of a transcriptional replication-competent adenovirus, Ad-OC-E1a, for osteosarcoma pulmonary metastasis. J. Gene Med. 2006, 8, 679-689. [CrossRef] [PubMed]

20. Graat, H.C.A.; van Beusechem, V.W.; Schagen, F.H.E.; Witlox, M.A.; Kleinerman, E.S.; Helder, M.N.; Gerritsen, W.R.; Kaspers, G.J.L.; Wuisman, P.I. Intravenous administration of the conditionally replicative adenovirus Ad5-Delta24RGD induces regression of osteosarcoma lung metastases. Mol. Cancer 2008, 7, 9. [CrossRef] [PubMed]

21. Martinez-Velez, N.; Xipell, E.; Vera, B.; de la Rocha, A.A.; Zalacain, M.; Marrodan, L.; Gonzalez-Huarriz, M.; Toledo, G.; Cascallo, M.; Alemany, R.; et al. The oncolytic adenovirus ven-01 as therapeutic approach against pediatric osteosarcoma. Clin. Cancer Res. 2016, 22, 2217-2225. [CrossRef] [PubMed]

22. Kolb, E.A.; Sampson, V.; Stabley, D.; Walter, A.; Sol-Church, K.; Cripe, T.; Hingorani, P.; Ahern, C.H.; Weigel, B.J.; Zwiebel, J.; et al. A phase I trial and viral clearance study of reovirus (Reolysin) in children with relapsed or refractory extra-cranial solid tumors: A Children's Oncology Group Phase I Consortium report. Pediatr. Blood Cancer 2015, 62, 751-758. [CrossRef] [PubMed]

23. Marchini, A.; Bonifati, S.; Scott, E.M.; Angelova, A.L.; Rommelaere, J. Oncolytic parvoviruses: From basic virology to clinical applications. Virol. J. 2015, 12, 6. [CrossRef] [PubMed]

24. Toolan, H.W.; Rhode, S.L., III; Gierthy, J.F. Inhibition of 7,12-dimethylbenz(a)anthracene-induced tumors in Syrian hamsters by prior infection with H-1 parvovirus. Cancer Res. 1982, 42, 2552-2555. [PubMed]

25. Toolan, H.W.; Saunders, E.L.; Southam, C.M.; Moore, A.E.; Levin, A.G. H-1 virus viremia in the human. Proc. Soc. Exp. Biol. Med. 1965, 119, 711-715. [CrossRef] [PubMed]

26. Angelova, A.L.; Geletneky, K.; Nüesch, J.P.; Rommelaere, J. Tumor selectivity of oncolytic parvoviruses: From in vitro and animal models to cancer patients. Front. Bioeng. Biotechnol. 2015, 3, 55. [CrossRef] [PubMed]

27. Cripe, T.P.; Ngo, M.C.; Geller, J.I.; Louis, C.U.; Currier, M.A.; Racadio, J.M.; Towbin, A.J.; Rooney, C.M.; Pelusio, A.; Moon, A.; et al. Phase 1 study of intratumoral Pexa-Vec (JX-594), an oncolytic and immunotherapeutic vaccinia virus, in pediatric cancer patients. Mol. Ther. 2015, 23, 602-608. [CrossRef] [PubMed]

28. Nuesch, J.P.F.; Lacroix, J.; Marchini, A.; Rommelaere, J. Molecular pathways: Rodent parvoviruses-Mechanisms of oncolysis and prospects for clinical cancer treatment. Clin. Cancer Res. 2012, 18, 3516-3523. [CrossRef] [PubMed]

29. El-Andaloussi, N.; Endele, M.; Leuchs, B.; Bonifati, S.; Kleinschmidt, J.; Rommelaere, J.; Marchini, A. Novel adenovirus-based helper system to support production of recombinant parvovirus. Cancer Gene Ther. 2011, 18, 240-249. [CrossRef] [PubMed]

30. Weiss, N.; Stroh-Dege, A.; Rommelaere, J.; Dinsart, C.; Salome, N. An in-frame deletion in the NS protein-coding sequence of parvovirus H-1PV efficiently stimulates export and infectivity of progeny virions. J. Virol. 2012, 86, 7554-7564. [CrossRef] [PubMed]

31. De Veas, R.G.; Schweigerer, L.; Medina, M.A. Modulation of the proteolytic balance plasminogen activator/plasminogen activator inhibitor by enhanced N-myc oncogene expression or application of genistein. Eur. J. Cancer 1998, 34, 1736-1740. [CrossRef]

32. Castro, F.; Dirks, W.G.; Fahnrich, S.; Hotz-Wagenblatt, A.; Pawlita, M.; Schmitt, M. High-throughput SNP-based authentication of human cell lines. Int. J. Cancer 2013, 132, 308-314. [CrossRef] [PubMed]

33. Schmitt, M.; Pawlita, M. High-throughput detection and multiplex identification of cell contaminations. Nucleic Acids Res. 2009, 37, e119. [CrossRef] [PubMed]

34. Wrzesinski, C.; Tesfay, L.; Salome, N.; Jauniaux, J.C.; Rommelaere, J.; Cornelis, J.; Dinsart, C. Chimeric and pseudotyped parvoviruses minimize the contamination of recombinant stocks with replication-competent viruses and identify a dna sequence that restricts parvovirus h-1 in mouse cells. J. Virol. 2003, 77, 3851-3858. [CrossRef] [PubMed]

35. Leuchs, B.; Roscher, M.; Muller, M.; Kurschner, K.; Rommelaere, J. Standardized large-scale H-1PV production process with efficient quality and quantity monitoring. J. Virol. Methods 2016, 229, 48-59. [CrossRef] [PubMed] 
36. Kestler, J.; Neeb, B.; Struyf, S.; van Damme, J.; Cotmore, S.F.; D'Abramo, A.; Tattersall, P.; Rommelaere, J.; Dinsart, C.; Cornelis, J.J. Cis requirements for the efficient production of recombinant DNA vectors based on autonomous parvoviruses. Hum. Gene Ther. 1999, 10, 1619-1632. [CrossRef] [PubMed]

37. Rayet, B.; Lopez-Guerrero, J.A.; Rommelaere, J.; Dinsart, C. Induction of programmed cell death by parvovirus H-1 in U937 cells: Connection with the tumor necrosis factor alpha signalling pathway. J. Virol. 1998, 72, 8893-8903. [PubMed]

38. Herrero y Calle, M.; Cornelis, J.J.; Herold-Mende, C.; Rommelaere, J.; Schlehofer, J.R.; Geletneky, K. Parvovirus H-1 infection of human glioma cells leads to complete viral replication and efficient cell killing. Int. J. Cancer 2004, 109, 76-84. [CrossRef] [PubMed]

39. Lacroix, J.; Leuchs, B.; Li, J.; Hristov, G.; Deubzer, H.E.; Kulozik, A.E.; Rommelaere, J.; Schlehofer, J.R.; Witt, O. Parvovirus H1 selectively induces cytotoxic effects on human neuroblastoma cells. Int. J. Cancer 2010, 127, 1230-1239. [CrossRef] [PubMed]

40. Hristov, G.; Krämer, M.; Li, J.; El-Andaloussi, N.; Mora, R.; Daeffler, L.; Zentgraf, H.; Rommelaere, J.; Marchini, A. Through its nonstructural protein NS1, parvovirus H-1 induces apoptosis via accumulation of reactive oxygen species. J. Virol. 2010, 84, 5909-5922. [CrossRef] [PubMed]

41. Toolan, H.W. Lack of oncogenic effect of the H-viruses for hamsters. Nature 1967, 214, 1036. [CrossRef] [PubMed]

42. Faisst, S.; Faisst, S.R.; Dupressoir, T.; Plaza, S.; Pujol, A.; Jauniaux, J.C.; Rhode, S.L.; Rommelaere, J. Isolation of a fully infectious variant of parvovirus H-1 supplanting the standard strain in human cells. J. Virol. 1995, 69, 4538-4543. [PubMed]

43. Olijslagers, S.; Dege, A.Y.; Dinsart, C.; Voorhoeve, M.; Rommelaere, J.; Noteborn, M.H.; Cornelis, J.J. Potentiation of a recombinant oncolytic parvovirus by expression of Apoptin. Cancer Gene Ther. 2001, 8, 958-965. [CrossRef] [PubMed]

44. Lacroix, J.; Schlund, F.; Leuchs, B.; Adolph, K.; Sturm, D.; Bender, S.; Hielscher, T.; Pfister, S.M.; Witt, O.; Rommelaere, J.; et al. Oncolytic effects of parvovirus H-1 in medulloblastoma are associated with repression of master regulators of early neurogenesis. Int. J. Cancer 2014, 134, 703-716. [CrossRef] [PubMed]

45. Hashemi, H.; Stroh-Dege, A.Y.; Weiss, N.; Condurat, L.; Geiss, C.; Pilet, J.; Cornet-Bartolomé, C.; Rommelaere, J.; Salomé, N.; Dinsart, C. Mutations in the NS protein-coding sequence of protoparvovirus $\mathrm{H}-1 \mathrm{PV}$ enhance the fitness of the virus and show key benefits regarding the transduction efficiency of H-1PV-based vectors. Viruses 2017. submitted.

(C) 2017 by the authors. Licensee MDPI, Basel, Switzerland. This article is an open access article distributed under the terms and conditions of the Creative Commons Attribution (CC BY) license (http:// creativecommons.org/licenses/by/4.0/). 